\title{
ANALISIS PERFORMA PROTOKOL GPSR DAN GPSR-HLS \\ PADA JARINGAN VEHICULAR AD HOC NETWORK (VANET)
}

\section{Skripsi}

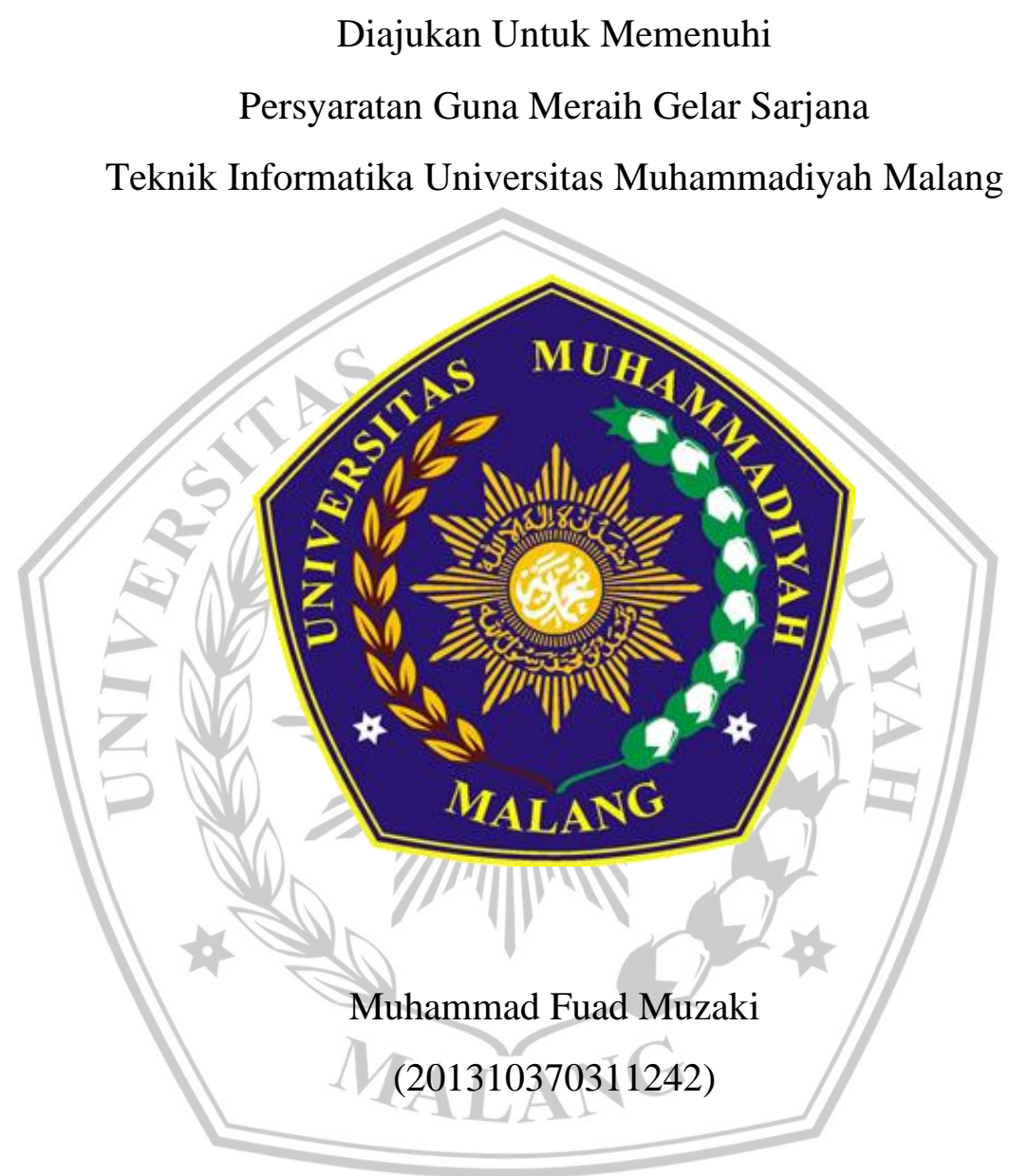

Bidang Minat

Jaringan

PROGRAM STUDI TEKNIK INFORMATIKA

FAKULTAS TEKNIK

UNIVERSITAS MUHAMMADIYAH MALANG 


\title{
ANALISIS PERFORMA PROTOKOL GPSR DAN GPSR-HLS \\ PADA JARINGAN VEHICULAR AD HOC NETWORK (VANET)
}

\author{
Muhammad Fuad Muzaki \\ 201310370311242 \\ Telah Direkomendasikan Untuk Diajukan Sebagai \\ Judul Tugas Akhir Di \\ Teknik Informatika Universitas Muhammadiyah Malang
}

Menyetujui,

Pembimbing I

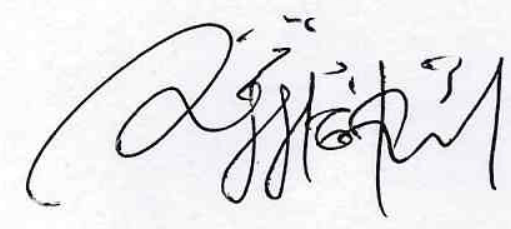

Denar Regata A, S.Kom., M.Kom. NIDN. 0701058601
Pembimbing II

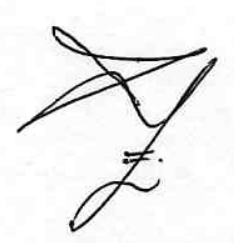

Svaifuddin, S.Kom., M.Kom. NIDN. 0716118701 


\title{
LEMBAR PENGESAHAN
}

ANALISIS PERFORMA PROTOKOL GPSR DAN GPSR-HLS PADA JARINGAN VEHICULAR AD HOC NETWORK (VANET)

\author{
Tugas Akhir
}

Sebagai Persyaratan Guna Meraih Gelar Sarjana Strata 1
Teknik Informatika Universitas Muhammadiyah Malang

Disusun Oleh :

Muhammad Fuad Muzaki

201310370311242

Tugas Akhir ini telah diuji dan dinyatakan lulus melalui sidang majelis penguji pada tanggal 18 Juli 2020

Menyetujui,

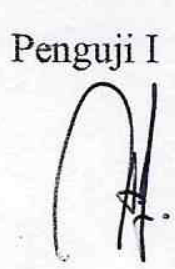

Mahar Faiqurahman A, S.Kom., M.T. NIP. 10808110462

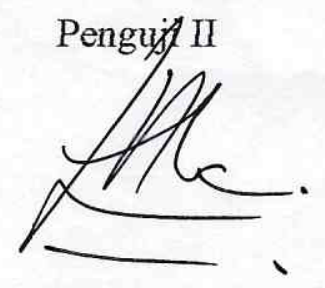

Luqman Hakim, S.Kom., M.Kom. NIP. 10819030658

Mengetahui,

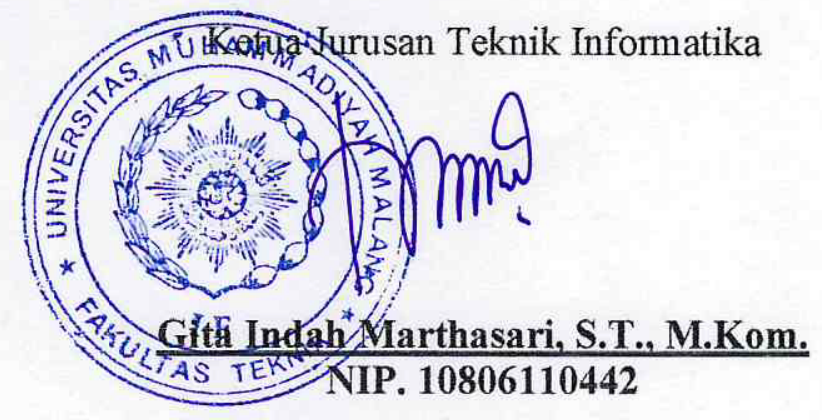




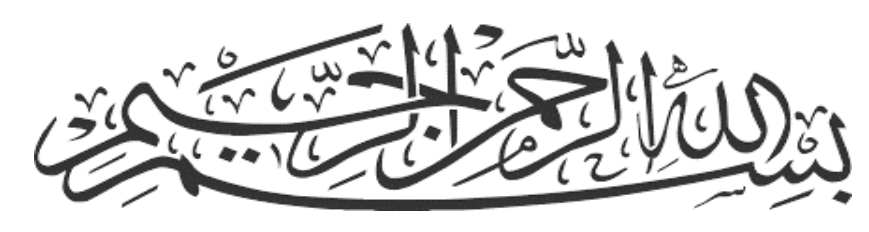

Assalamualaikum Wr. Wb.

Dengan memanjatkan puji syukur kehadirat Allah SWT yang telah memberikan rahmat dan hidayah-Nya kepada penulis sehingga dapat menyelesaikan skripsi sebagai tugas akhir. Berkat limpahan nikmat dan karunia yang telah Allah SWT berikan sehingga skripsi berjudul "Analisis Performa Protokol GPSR dan GPSR-HLS Pada Jaringan Vehicular Ad Hoc Network (VANET)" ini dapat terselesaikan. Skripsi ini dimaksudkan untuk memenuhi persyaratan guna memperoleh gelar sarjana S1 Universitas Muhammadiyah Malang.

Penulis menyadari bahwa sepenuhnya penulisan Tugas Akhir ini masih banyak kekurangan, oleh karena itu penulis mengharapkan saran dan kritik agar tulisan ini bermanfaat bagi pembaca maupun peneliti/lainnya/Akhir kata penulis mengucapkan terima kasih kepada semua pihak yang telah membantu sehingga terselesaikannya tugas akhir ini

Wassalamualaikum Wr. Wb.

Malang, 14 Oktober 2020

Muhammad Fuad Muzaki 


\section{LEMBAR PERNYATAAN}

Yang bertanda tangan di bawah ini :

Nama

: Muhammad Fuad Muzaki

Tempat, Tanggal lahir

: Blitar, 09 Maret 1993

NIM

: 201310370311242

Fakultas

: Teknik

Jurusan

: Teknik Informatika

Dengan ini saya menyatakan bahwa Tugas Akhir dengan judul "ANALISIS PERFORMA PROTOKOL GPSR DAN GPSR-HLS PADA JARINGAN VEHICULAR AD HOC NETWORK (VANET)" beserta seluru isinya adalah karya saya sendiri dan bukan merupakan karya tulis orang lain, baik sebagian maupun keseluruhan kecuali dalam bentuk kutipan yang telah disebutkan sumbernya.

Demikian surat pernyataan ini saya buat dengan sebenar-benarnya. Apabila kemudian ditemukan adanya pelanggaran terhadap etika keilmuan dalam karya saya ini, atau ada klaim dari pihak lain terhadap keaslian karya saya ini maka saya siap menanggung segala bentuk risiko atau sanksi yang berlaku.

Mengetahui

Dosen Pembimbing

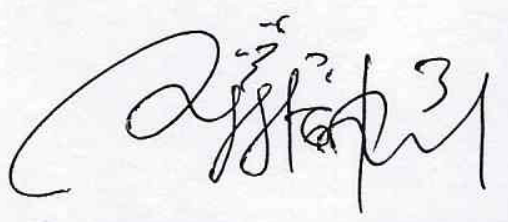

Denar Regata A, S.Kom., M.Kom. NIDN. 0701058601
Malang, 14 Oktober 2020

Yang membuat pernyataan

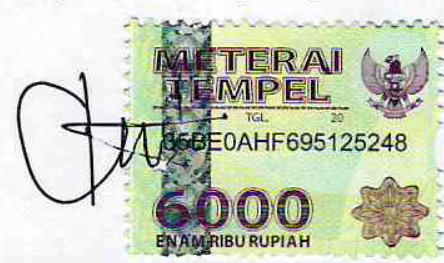

Muhammad Fuad Muzaki

NIM. 201310370311242 


\begin{abstract}
ABSTRAK
Salah satu karakteristik utama jaringan VANET yaitu kecepatan node yang tinggi sehingga menyebabkan topologi jaringan berubah secara cepat. Hal ini menjadi sebuah kendala dalam pengiriman paket data antara satu node dengan node lainnya. Tantangan yang dihadapi dalam VANET adalah pemilihan protokol routing yang tepat sesuai dengan skenario yang ada. Jenis protokol routing VANET dapat dikategorikan menjadi beberapa jenis yaitu protokol berbasis topologi, geografis, cluster, broadcast, dan geocast. Greedy Perimeter Stateless Routing (GPSR) adalah contoh protokol routing geografis yang menggunakan posisi node secara geografis untuk menentukan tujuan. Performa yang ditunjukkan protokol GPSR pada penelitian sebelumnya menunjukkkan performa yang cukup baik, tetapi masih ada kelemahan dalam mekanisme recovery pengiriman paket data. Metode yang bisa digunakan untuk menangani permasalahan tersebut adalah menggunakan Hierarchical Location Service (HLS) yaitu sebuah layanan untuk menentukan posisi node berdasarkan hierarki. Pengujian dengan skenario urban di Kota Malang berdasarkan kecepatan maksimal node, jumlah node, dan ukuran paket data menunjukkan performa protokol GPSR-HLS mengalami peningkatan dalam jumlah paket data yang diterima di node penerima hingga di atas $95 \%$ pada ketiga skenario.

Kata kunci: VANET, GPSR, HLS
\end{abstract}




\begin{abstract}
One of the main characteristics of VANET networks is the high node speed, which causes the network topology to change rapidly. This becomes an obstacle in sending data packets between one node and another node. The challenge faced in VANET is choosing the right routing protocol in accordance with the existing scenario. Types of VANET routing protocols can be categorized into several types, namely topology, geographic, cluster, broadcast and geocast based protocols. Greedy Perimeter Stateless Routing (GPSR) is an example of a geographical routing protocol that uses the position of a node geographically to determine its destination. The performance shown by the GPSR protocol in previous studies shows a fairly good performance, but there are still weaknesses in the recovery mechanism of sending data packets. The method that can be used to deal with these problems is to use Hierarchical Location Service (HLS), which is a service to determine the position of a node based on a hierarchy. Testing with urban scenarios in Malang based on the maximum node speed, number of nodes, and data packet size shows the performance of the GPSR-HLS protocol has increased in the number of data packets received at the receiving node to above $95 \%$ in all three scenarios.
\end{abstract}

Keywords: VANET, GPSR, HLS
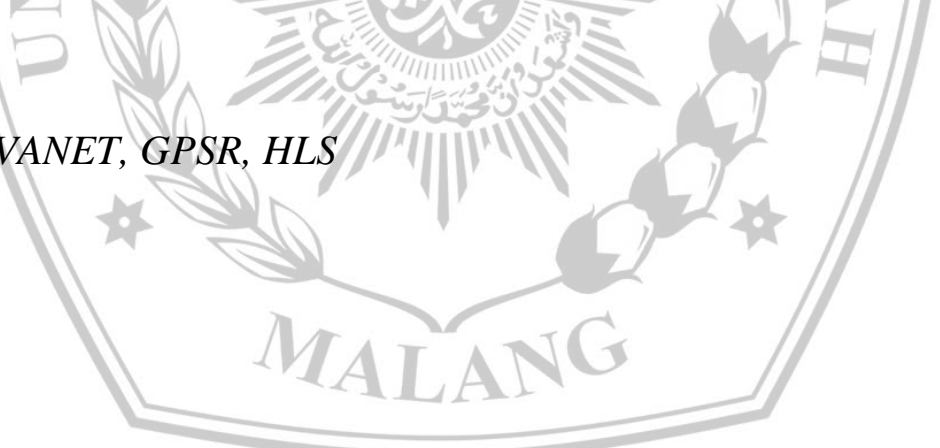


\section{DAFTAR ISI}

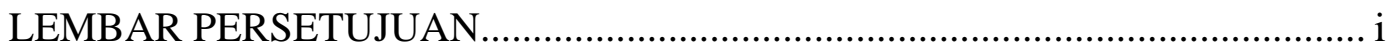

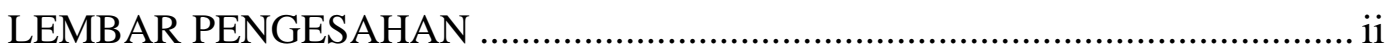

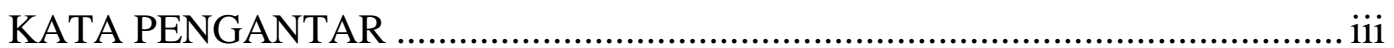

LEMBAR PERNYATAAN ................................................................ iv

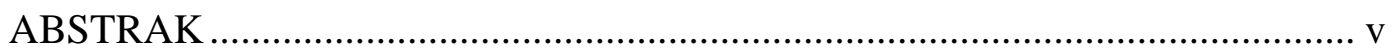

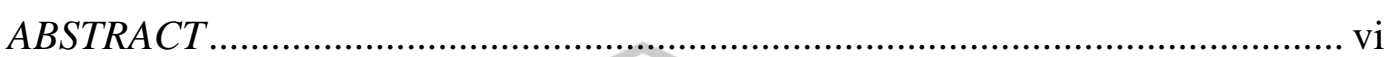

DAFTAR ISI ....................................................................................... vii

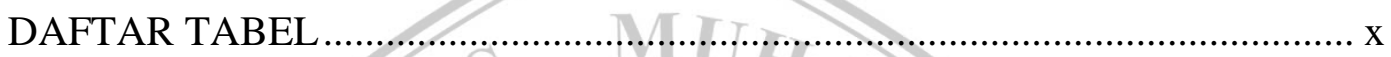

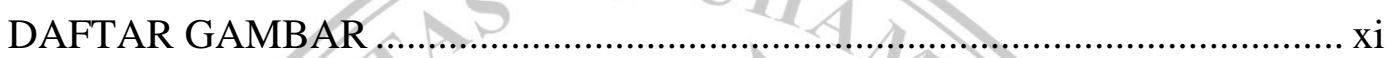

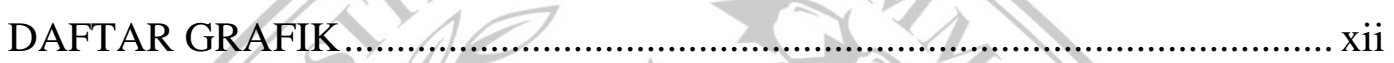

BAB I PENDAHULUAN ................................................................... 1

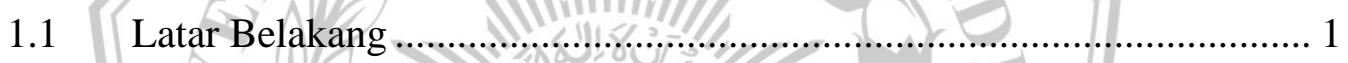

1.2 Rumusan Masalah ................................................................. 3

1.3 Tujuán Penelitian ................................................................... 3

1.4 Batasan Masalah,.......................................................................... 3

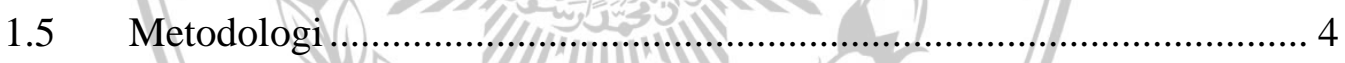

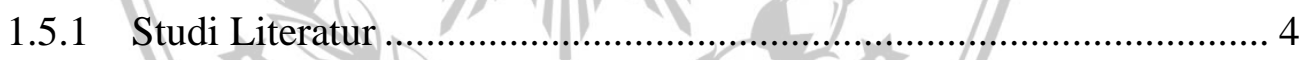

1.5.2 Perancangan Sistem .................................................................. 5

1.5.3 Implementasi Sistem ............................................................ 7

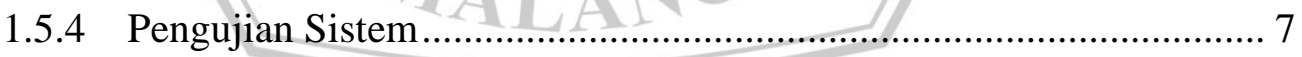

1.5.5 Pembuatan Laporan Akhir .......................................................... 7

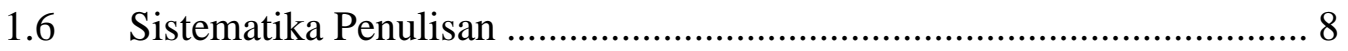

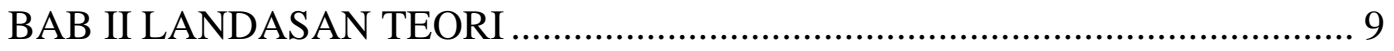

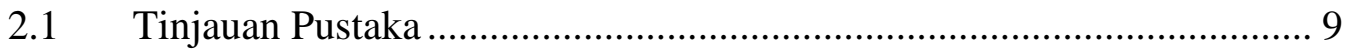

2.2 Vehicular Ad hoc Network (VANET) .............................................. 10

2.3 Greedy Perimeter Stateless Routing (GPSR).................................... 11

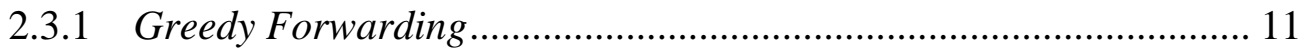

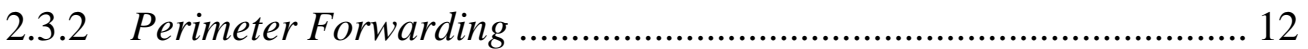

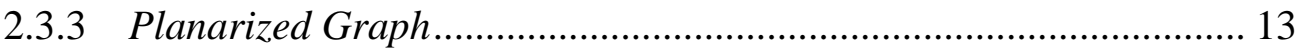

$2.4 \quad$ Hierarchical Location Service (HLS) ................................................ 14 


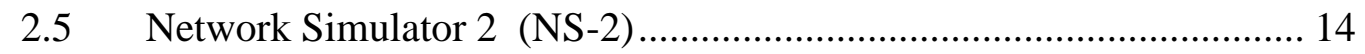

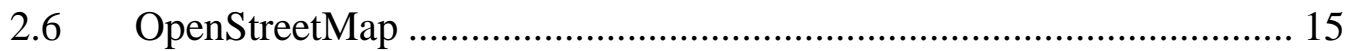

2.7 Simulation of Urban Mobility (SUMO) .............................................. 16

$2.8 \quad$ Java OpenStreetmap Editor (JOSM) ............................................. 17

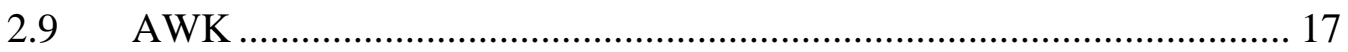

BAB III METODE PENELITIAN_................................................................. 18

3.1 Kebutuhan Sistem ...................................................................... 18

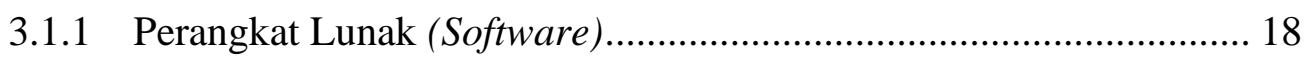

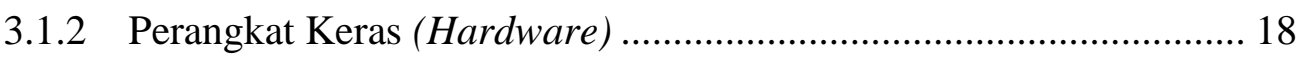

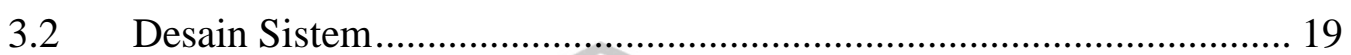

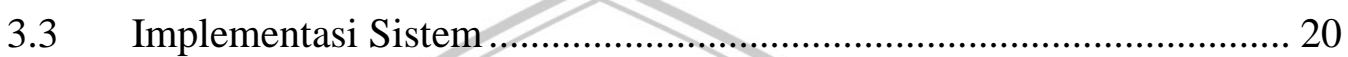

3.3.1 Membangun Lingkungan Pengujian ............................................ 20

3.3.2 Perancangan Skenario Mobilitas .................................................. 21

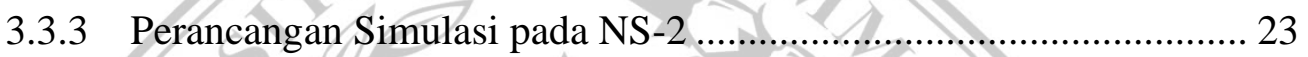

3.4 Skenario Pengujian Sistem.......................................................... 23

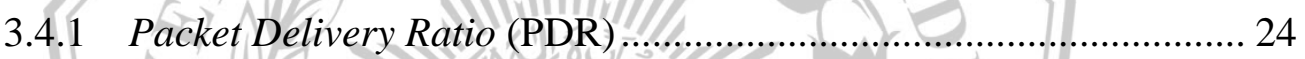

3.4.2 Packet Loss ....................................................................... 24

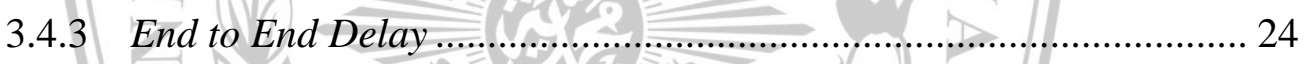

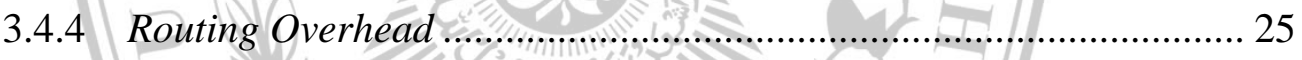

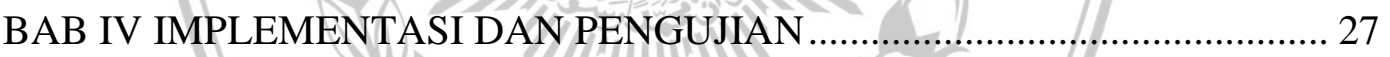

4.1 Instalasi dan Konfigurasi.......................................................... 27

4.1.1 Instalasi Network Simulator 2 (NS-2) ...................................... 27

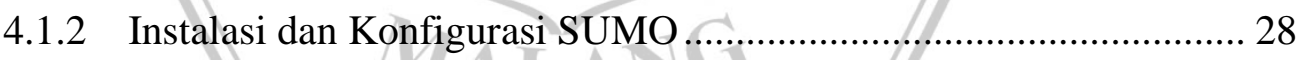

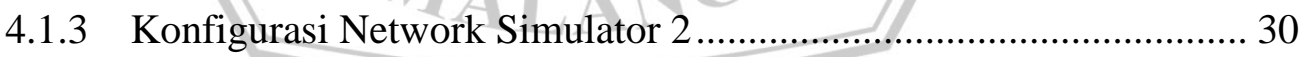

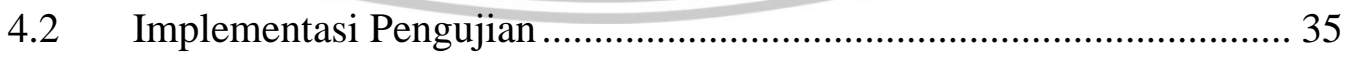

4.3 Hasil Pengujian Protokol GPSR dan GPSR-HLS (Node Statis)........... 38

4.3.1 Hasil Pengujian dengan Skenario Kecepatan Maksimal.................. 38

4.3.2 Hasil Pengujian dengan Skenario Jumlah Node ............................. 42

4.3.3 Hasil Pengujian dengan Skenario Ukuran Paket Data ..................... 47

4.4 Hasil Pengujian Protokol GPSR dan GPSR-HLS (Node Dinamis)...... 51

4.4.1 Hasil Pengujian dengan Skenario Kecepatan Maksimal.................. 51

4.4.2 Hasil Pengujian dengan Skenario Jumlah Node .............................. 55

4.4.3 Hasil Pengujian dengan Skenario Ukuran Paket Data ..................... 60

4.5 Perbandingan Hasil Pengujian Node Statis dan Node Dinamis ............ 64 


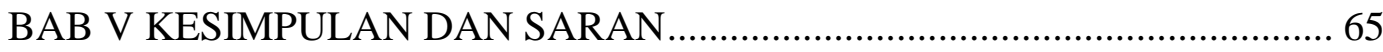

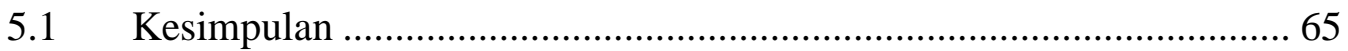

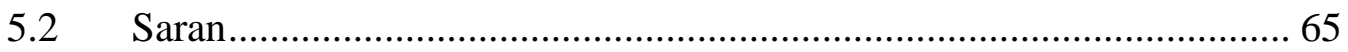

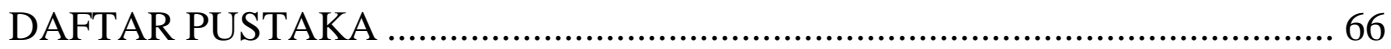

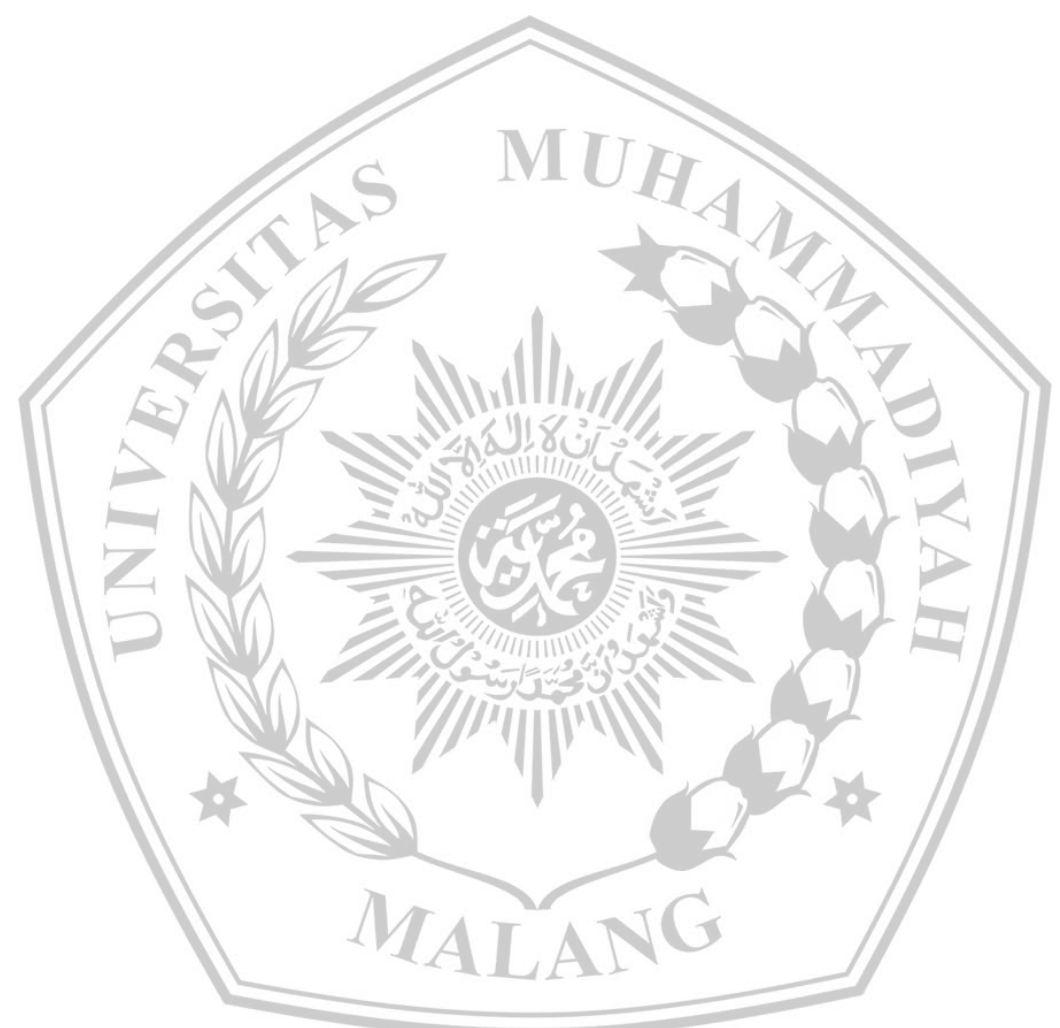




\section{DAFTAR TABEL}

Tabel 1.1 Perbandingan Penelitian.................................................................... 5

Tabel 3.1 Parameter Simulasi NS-2 _................................................................ 23

Tabel 3.2 Pengujian Berdasarkan Kecepatan.................................................. 25

Tabel 3.3 Pengujian Berdasarkan Jumlah Node .................................................. 25

Tabel 3.4 Pengujian Berdasarkan Ukuran Paket Data ......................................... 26

Tabel 4.1 Packet Loss Skenario Kecepatan ....................................................... 38

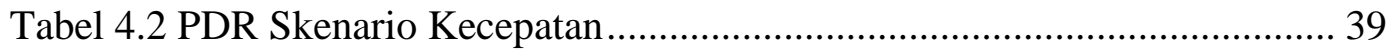

Tabel 4.3 End to End Delay Skenario Kecepatan .............................................. 40

Tabel 4.4 Routing Overhead Skenario Kecepatan ............................................. 41

Tabel 4.5 Packet Loss Skenario Jumlah Node ................................................ 42

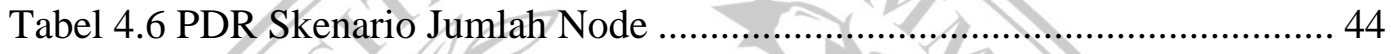

Tabel 4.7 End to End Delay Skenario Jumlah Node......................................... 45

Tabel 4.8 Routing Overhead Skenario Jumlah Node......................................... 46

Tabel 4.9 Packet Loss Skenario Ukuran Paket Data ......................................... 47

Tabel 4.10 PDR Skenario Ukuran Paket Data …........................................... 48

Tabel 4.11 End to End Delay Skenario Ukuran Paket Data .............................. 49

Tabel 4.12 Routing Overhead Skenario Ukuran Paket Data............................. 50

Tabel 4.13 Packet Loss Skenario Kecepatan .................................................. 51

Tabel 4.14 PDR Skenario Kecepatan .......................................................... 52

Tabel 4.15 End to End Delay Skenario Kecepatan .......................................... 53

Tabel 4.16 Routing Overhead Skenario Kecepatan .......................................... 54

Tabel 4.17 Packet Loss Skenario Jumlah Node ................................................. 56

Tabel 4.18 PDR Skenario Jumlah Node ......................................................... 57

Tabel 4.19 End to End Delay Skenario Jumlah Node........................................ 58

Tabel 4.20 Routing Overhead Skenario Jumlah Node......................................... 59

Tabel 4.21 Packet Loss Skenario Ukuran Paket Data.......................................... 60

Tabel 4.22 PDR Skenario Ukuran Paket Data .................................................... 61

Tabel 4.23 End to End Delay Skenario Ukuran Paket Data ................................ 62

Tabel 4.24 Routing Overhead Skenario Ukuran Paket Data............................... 63 


\section{DAFTAR GAMBAR}

Gambar 1.1 Diagram Alir Metode Penelitian .................................................... 4

Gambar 1.2 Flowchart Perancangan Sistem ........................................................ 6

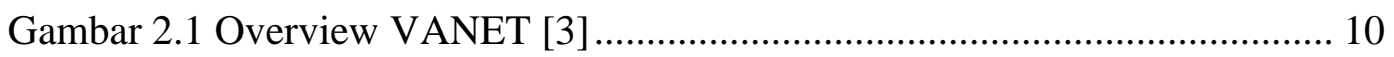

Gambar 2.2 Ilustrasi Greedy Forwarding [10] ................................................ 12

Gambar 2.3 Ilustrasi Pemilihan Neighbour Greedy Forwarding [10].................. 12

Gambar 2.4 Right Hand Rule [10] ................................................................ 13

Gambar 2.5 Relative Neighbour Graph [10] ................................................. 13

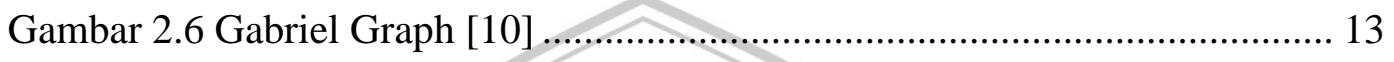

Gambar 2.7 Metode Hierarchichal Location Service [11] ................................. 14

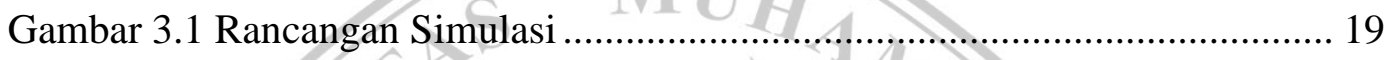

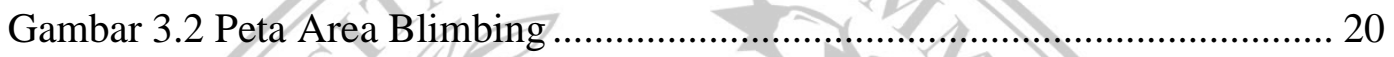

Gambar 3.3 Peta Hasil Konversi ............................................................... 21

Gambar 3.4 Alur Pembuatan Skenario Mobilitas .......................................... 22

Gambar 4.1 Tampilan Peta di Aplikasi SUMO ….......................................... 28

Gambar 4.2 File Config SUMO .............................................................. 29

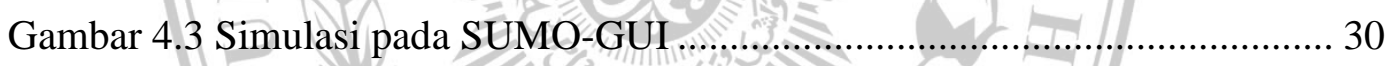

Gambar 4.4 Struktur Folder Simulasi GPSR .............................................. 31

Gambar 4.5 Potongan Kode File 40maxspeednode.tcl .................................... 32

Gambar 4.6 Potongan Kode File 40maxpeednode.tcl....................................... 32

Gambar 4.7 Potongan Kode file 40max speednode.tcl ...................................... 32

Gambar 4.8 Potongan Kode file mobility.tcl ................................................... 33

Gambar 4.9 Potongan Kode File 40eks.tcl...................................................... 33

Gambar 4.10 Potongan Kode File 40maxspeed.tcl ............................................ 34

Gambar 4.11 Potongan Kode File 40maxspeed.tcl ........................................... 34

Gambar 4.12 Potongan Kode File mobility.tcl .............................................. 35

Gambar 4.13 Menjalakan Simulasi GPSR …............................................... 36

Gambar 4.14 Menjalankan Simulasi GPSR-HLS .............................................. 36

Gambar 4.15 Simulai NAM Berbasis GUI ....................................................... 37

Gambar 4.16 Menjalankan Skrip Analisis AWK............................................. 37

Gambar 4.17 Menjalankan Skrip Analisis AWK............................................. 37 


\section{DAFTAR GRAFIK}

Grafik 4.1 Packet Loss Skenario Kecepatan ...................................................... 38

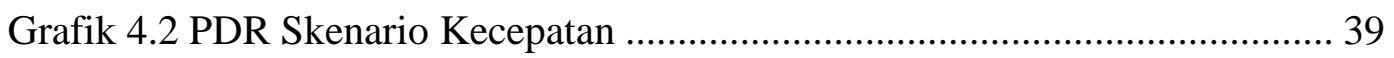

Grafik 4.3 End to End Delay Skenario Kecepatan............................................ 40

Grafik 4.4 Routing Overhead Skenario Kecepatan .......................................... 42

Grafik 4.5 Packet Loss Skenario Jumlah Node.................................................. 43

Grafik 4.6 PDR Skenario Jumlah Node ............................................................. 44

Grafik 4.7 End to End Delay Skenario Jumlah Node ......................................... 45

Grafik 4.8 Routing Overhead Skenario Jumlah Node ........................................ 46

Grafik 4.9 Packet Loss Skenario Ukuran Paket Data ........................................ 47

Grafik 4.10 PDR Skenario Ukuran Paket Data............................................... 48

Grafik 4.11 End to End Delay Skenario Ukuran Paket Data ............................. 49

Grafik 4.12 Routing Overhead Skenario Ukuran Paket Data ............................. 50

Grafik 4.13 Packet Loss Skenario Kecepatan ............................................... 51

Grafik 4.14 PDR Skenario Kecepatan ....................................................... 52

Grafik 4.15 End to End Delay Skenario Kecepatan.........................................53

Grafik 4.16 Routing Overhead Skenario Kecepatan ....................................... 55

Grafik 4.17 Packet Loss Skenario Jumlah Node............................................. 56

Grafik 4.18 PDR Skenario Jumlah Node ..................................................... 57

Grafik 4.19 End to End Delay Skenario Jumlah Node ...................................... 58

Grafik 4.20 Routing Overhead Skenario Jumlah Node ................................... 59

Grafik 4.21 Packet Loss Skenario Ukuran Paket Data ....................................... 60

Grafik 4.22 PDR Skenario Ukuran Paket Data................................................ 61

Grafik 4.23 End to End Delay Skenario Ukuran Paket Data ............................. 62

Grafik 4.24 Routing Overhead Skenario Ukuran Paket Data ............................ 63 


\section{DAFTAR PUSTAKA}

[1] M. M. Zanjireh and H. Larijani, "A survey on centralised and distributed clustering routing algorithms for WSNs," IEEE Veh. Technol. Conf., vol. 2015, no. May, 2015.

[2] M. M. Zanjireh, A. Shahrabi, and H. Larijani, "ANCH: A new clustering algorithm for wireless sensor networks," Proc. - 27th Int. Conf. Adv. Inf. Netw. Appl. Work. WAINA 2013, no. March, pp. 450-455, 2013.

[3] M. Sivasakthi, S. S.-S. and E. Research, and undefined 2013, "Research on vehicular ad hoc networks (VANETs): an overview," indianjournals.com.

[4] - 2017 2nd IEEE International Conference on H Kaur, Meenakshi and U. 2017, "Analysis of VANET geographic routing protocols on real city map," ieeexplore.ieee.org.

[5] R. Dian Prasetia, D. Perdana, and R. Muldina Negara, "Analisis Kinerja GPSR dan AODV pada VANET dengan Skema Pengimbangan Beban Trafik,"vol. ISSN, no. 2, pp. 207-218, 2018.

[6] S. Boussoufa-Lahlah, ...F.S.-V., and undefined 2018, "Geographic routing protocols for Vehicular Ad hoc NETworks (VANETs): A survey," Elsevier.

[7] M. Zayene, ... N. T.-2009 F. I., and 2009, "Performance evaluation of greedy perimeter stateless routing protocol in ad hoc networks," ieeexplore.ieee.org.

[8] K. Arditya, S. Djanali, and R. Anggoro, "Implementasi Konsep Overlay Network pada Greedy Perimeter Stateless Routing (GPSR) di VANETs," J. Tek. ITS, vol. 6, no. 2, pp. 317-320, 2017.

[9] A. Fitah, A. Badri, M. Moughit, A. S.-P. C. Science, and undefined 2018, "Performance of DSRC and WIFI for Intelligent Transport Systems in VANET," Elsevier. 
[10] B. Karp and H. T. Kung, "GPSR: Greedy Perimeter Stateless Routing for Wireless Networks.”

[11] W. Kieß, H. Füßler, J. Widmer, and M. Mauve, "Hierarchical location service for mobile ad-hoc networks," ACM SIGMOBILE Mob. Comput. Commun. Rev., vol. 8, no. 4, pp. 47-58, Oct. 2004.

[12] “The Network Simulator - ns-2." [Online]. Available: https://www.isi.edu/nsnam/ns/. [Accessed: 01-Jul-2020].

[13] “OpenStreetMap.” [Online]. Available: https://www.openstreetmap.org/about. [Accessed: 01-Jul-2020].

[14] “About Eclipse SUMO | Eclipse SUMO - Simulation of Urban MObility." [Online]. Available: https://www.eclipse.org/sumo/about/. [Accessed: 01Jul-2020].

[15] “JOSM." [Online]. Available: https://josm.openstreetmap.de/. [Accessed: 01-Jul-2020].

[16] “Awk - A Tutorial and Introduction - by Bruce Barnett." [Online]. Available: https://www.grymoire.com/Unix/Awk.html. [Accessed: 01-Jul2020].

[17] J. Ericka, W. Prakasa, R. Anggoro, and W. Wibisono, "OPTIMASI KINERJA PROTOKOL AODV DENGAN STATIC INTERSECTION NODE," 2016.

[18] F. D. S. S, A. G. L. N, P. A. W, H. W. P. Richo, and N. Edwin, “Analisis Performansi Protokol Routing AODV dan DSR pada MANET." 


\section{UNIVERSITAS MUHAMMADIYAH MALANG FAKULTAS TEKNIK PROGRAM STUDI TEKNIK INFORMATIKA \\ Jl. Raya Tlogomas 246 Malang 65144 Telp. 0341 - 464318 Ext. 247, Fax. 0341 - 460782}

\section{FORM CEK PLAGIARISME LAPORAN TUGAS AKHIR}

Nama Mahasiswa : MUHAMMAD FUAD MUZAKI

NIM

: 201310370311242

Judul TA

: ANALISIS PERFORMA PROTOKOL GPSR DAN GPSR-HLS

PADA JARINGAN VEHICULAR AD HOC NETWORK (VANET)

Hasil Cek Plagiarisme dengan Turnitin

\begin{tabular}{|l|l|c|c|}
\hline No. & \multicolumn{1}{|c|}{ Komponen Pengecekan } & $\begin{array}{c}\text { Nilai Maksimal } \\
\text { Plagiarisme (\%) }\end{array}$ & $\begin{array}{c}\text { Hasil Cek Plagiarisme } \\
\mathbf{( \% )} *\end{array}$ \\
\hline 1. & Bab 1 - Pendahuluan & $10 \%$ & 5 \\
\hline 2. & Bab 2 - Landasan Teori & $25 \%$ & $10 \%$ \\
\hline 3. & Bab 3 - Analisis dan Perancangan & $25 \%$ & $10 \%$ \\
\hline 4. & Bab 4 - Implementasi dan Pengujian & $15 \%$ & 36 \\
\hline 5. & Bab 5 - Kesimpulan dan Saran & $5 \%$ & $4 \%$ \\
\hline 6. & Makalah Tugas Akhir & $20 \%$ & \\
\hline
\end{tabular}

Mengetahui,

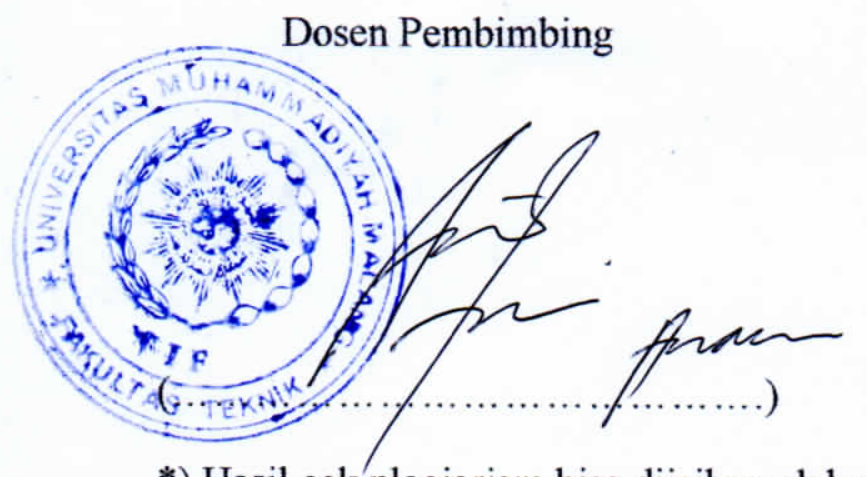

*) Hasil cek plagiarism bisa diisikan oleh salah satu pembimbing 